\title{
Enterprise search: a state of the art.
}

\author{
CLEVERLEY, P.H., BURNETT, S.
}

2019 


\title{
Enterprise Search: A State of the Art
}

\author{
Paul H. Cleverley \\ Robert Gordon University, UK \\ Simon Burnett \\ Robert Gordon University, UK
}

\begin{abstract}
Enterprise search is changing. The explosion of information within organizations, technological advances and availability of free OpenSource machine learning libraries offer many possibilities. Eighteen informants from practice, academia, search technology vendors and large organizations (Oil \& Gas, Governments, Pharmaceuticals, Aerospace and Retail) were interviewed to assess challenges and future directions. The findings confirmed the existence of the 'Google Habitus', technology propaganda and a need to transcend disciplines for a Systems thinking approach toward enterprise search. This encompasses information management, user search literacy, governance, learning feedback loops as well as technology. A novel four-level model for enterprise search use cases is presented, covering search as a utility, search as an answer machine, search task apps and a discovery engine. This could be used to reframe enterprise search perceptions, expanding possibilities and improving business outcomes.
\end{abstract}

Keywords: enterprise search \& discovery, cognitive search, insight engines, information management, information literacy

\section{INTRODUCTION}

Google and its search engine technology have been extremely successful in addressing the human desire to seek information. We make three and a half billion search queries every day on the Internet, increasing approximately 10\% year on year (Google 2015), where some scholars argue 'Google' has achieved consecrated status (Hillis, Petit and Jarrett 2013) and become a verb (Seltzer and Murphy 2009). Google may have become humanity's exobrain, extending our brainpower through almost instantaneous access to information (DiMaio 2009).

Digital information volumes are increasing exponentially inside organizations (Gantz and Reinsell 2011, Gartner 2011). This offers the potential for both overwhelming information overload and fascinating levels of information access and serendipitous information discovery (Dörk, Carpendale and Williamson 2011).

In response to this need to find information faster and more efficiently, organizations across a wide range of sectors have invested in Enterprise Search technologies, creating organizational exobrains, to allow staff to search and exploit their organization's distributed information repositories (such as documents, web pages, images and databases) for other people's information. Some organizations have digitally transformed through this process enabling better decisions and even the creation of new business models (Marr 2018).

User satisfaction with enterprise search has been notoriously difficult to achieve. Questions are being asked by both practitioners and academics how the traditional 'search box and ten blue links' approach fits with the possibilities presented by advances in technology and the explosion of big data. 
The goal of this research study is to understand the current challenges and future directions for enterprise search and to develop a conceptual model for enterprise search use cases. The next section briefly reviews the literature in this area.

\section{LITERATURE REVIEW}

Enterprise Search engines facilitate the re-use and exploitation of organizational information, to share and create new knowledge, saving time and supporting decision making, so are a key part of the digital workspace (White 2012, Kruschwitz and Hull 2017).

Whilst the early literature in the discipline focused on the Information Retrieval (IR) challenges in the enterprise (Hawking 2004), later literature took a more holistic view to cover the whole system include concepts such as the business case, information management (content), user behaviours, training, information literacy, governance and management expectation (Grant and Schymik 2014, White 2015, Gardelov et al 2015, Stocker et al 2015, Cleverley et al 2017, Cleverley and Burnett 2019). In addition, the early focus on web pages and document media has expanded to structured data, images, voice search (Betts 2018) and Augmented Reality (AR) in the form of a Digital Twin (Tao 2019).

Due to advances in technology, including Natural Language Processing (NLP) to detect meaning and Machine Learning for prediction (what technology marketing departments increasingly call Artificial Intelligence (AI)), we may be on the cusp of an inflexion point in how we manage and exploit information in organizations (Grefenstette and Wilber 2011). For example, Mukherjee et al (2013) claim that traditional IR systems are not effective in addressing the aims of knowledge workers who may ask a question such as 'How did we handle this case before?'. Technological breakthroughs also enable the surfacing of answers rather than lists (Seo et al 2017). The terms 'insight engine' and 'cognitive search' have even been suggested as terms to replace 'enterprise search' as terminology as this has been deemed as too narrow to reflect the emerging possibilities to interrogate information repositories (Tetu 2016, Gualtieri 2017).

There have been numerous enterprise search surveys (Findwise 2016, Mindmeter 2011), organizational case studies (Dale 2016;2013, Romero 2013, Meza and Berndt 2014), practitioner (Kehoe 2018, Landqvist 2019, Zarrabian 2019) technology vendor (Phillipson 2014) and research consultancy commentaries on the challenges and future directions (Gartner 2015, Gualtieri 2017).

The objectives of this study are to ascertain from key informant groups, the current best practices and challenges to successful search environments, future directions for enterprise search and the development of a conceptual model for enterprise search use cases.

\section{METHODOLOGY}

A critical realist stance was adopted for the study. Other philosophies are not suited to 'why questions' or moving beyond what may be observable today towards a transformational change. Critical realism has an interpretive fallibilistic epistemology. As researchers we cannot separate ourselves from what we know and this influences our research question, paradigms, methods and findings. The knowledge of the world we obtain is therefore fallible, the accounts of the researcher and research participants may be partial, misguided and influenced by ideology (Potter and Lopez 2001). Knowledge obtained can however, be checked for its effectiveness by triangulating information sources.

Critical realism steers a course between agency (where people are not robots that always follow cultural norms) and structure, where there is a cultural habitus that shapes what people believe and 
how they behave (Tett 2015). As expressed by Sayer (2000, pg. 12), "A crucial implication of this ontology is the recognition of the possibility that powers may exist unexercised, and hence that what has happened or been known to have happened does not exhaust what could happen or have happened. Realist ontology therefore makes it possible to understand how we could be or become many things which currently we are not.". Critical realist philosophy may therefore allow us to consider transformative change in Enterprise Search and Discovery capability.

Unstructured interviews with key stakeholders in the enterprise search system were chosen as the data collection method. This is recommended when the researcher has gathered through previous research, enough understanding of the subject to have a robust outline for the interview, whilst remaining open to revising their understanding through informant dialogue (Patton 2015).

From a critical realist perspective, qualitative methods allow themes to emerge spontaneously that could not have been predicted in advance. These methods illuminate the complex network of events and processes surrounding the phenomena that cannot be represented through predefined experiments, categories or unchallenged commentaries. Qualitative studies can go beyond associations to the deeper causal mechanisms (Miles and Huberman 1994).

Key aspects of critical realist interviewing (Smith and Elger 2012) adopted for this study include:

- Focusing on specific events and examples rather than generalities

- Challenging the accounts on offer

- Encouraging respondents to compare their experiences of different settings

- Probing for details and explanations, testing theories and beliefs not just stories

- Raising queries about puzzles and contradictions

- Rehearsing provisional analyses with informants

A purposeful sampling strategy was undertaken (a sub-strategy of reputational sampling), identifying people with significant knowledge and/or influence (by reputation) "who can shed light on the inquiry issues" (Patton 2015, pg.268). A literature review provided names of leading search practitioners and technology vendors. A selection of large organizations, as enterprise search is perceived as more difficult in large organizations (Norling and Boye 2013), was made to identify common factors transcending industries. Requests for participation were made through email and the social networking site LinkedIN.

Four well known enterprise search individuals from academia and practice agreed to participate coded [P1-P4], four search technology vendors (two dominant vendors and two small/start-ups) coded [T1T4] and ten organizations (from Oil \& Gas, Pharmaceutical, Government, Aerospace and Retail) coded [01-010] for confidentiality reasons. This therefore consisted of 18 informants in total.

Interviews were conducted over the phone individually, lasting between 30 minutes to 1 hour. Notes were transcribed and a process of thematic mapping undertaken to identify the key themes for synthesis (Patton 2015) which were then compared to the literature.

\section{RESULTS}

There was confirmation of assertions made in the literature review that enterprise search deployments find it difficult to achieve user satisfaction, "Many people would say Enterprise Search is an IT tool that does not work (quite a few in my company)!" [02] 
Ten themes were identified which are described in turn and summarized with relations in a model at the end of this section. The implications of this model will then be discussed in the next section.

\section{Google \& Alexa Habitus}

The role of structure (culture) and its influence on expectation and behaviour was discussed by informants, including the Internet of Things (IoT), mobile and voice search.

"The world is driving the benchmarks. People's perceptions are now coloured by what is happening in the technology world, Internet of Things (IOT), mobile devices, connectivity, could not have dreamt of 20 years ago." [02].

This appeared common across industry sectors.

"People think search is simple. No doubt Yahoo, Apple, Google have changed people's views. With mobile technology and improvement of ease of search in everyday things, ingrained in how people work. Nobody thinks there is any complexity in search, expect good results" [03].

The gap between the consumer and enterprise world was highlighted.

"There is a lag between consumer/academia and the enterprise. Trend you are seeing, tied to consumerization of $I T$, consumers start to use experiences at home, expect those type of experiences behind firewall. That is the unspoken law/nature. We are seeing predictive search, intelligent notifications starting to emerge in consumer space. Always a good cue to look at what is happening in consumer space." [T1]

With some informants feeling it is going to get larger, not smaller.

"For all the talk and amount invested [in the enterprise], because of the resources the consumer world can bring, the gap between consumer based search and Enterprise Search will probably get larger" [T3]

Practitioners, technology vendors and organizations all appeared to recognize the influence of external culture on the enterprise search environment.

\section{Technology Vendor Propaganda}

Search technology vendors have a number of innovations, at the same time both they and practitioners recognized the role of commercial drivers in this space, though there was silence from organizations on this theme.

"Despite all the talk about API's, most content management system vendors, not in their best interests to allow you to get at their content; it's the industry software model right? Trap the content in your system and collect the maintenance for ten years" [T4]

The role of marketing and re-use of freely available code was discussed.

"A lot of material on the Internet and vendor sites is from Snake oil salesman, what passes for best practice is ...re-selling and re-badging of existing work." [P4]

Some informants highlighted that technology was being used as an answer for poor search experiences, which may lead to 'fixes that fail', paving the way for a repeated cycle of technology replacement. 
"Technology is viewed as a white knight, marketing is operating all the time telling people that technology will be the fix. It is not convenient to bring up the questions that technology does not solve problems." [P2]

The Fear of Missing Out (FOMO) on the latest technologies as a motivator for action was discussed.

\section{Rise of OpenSource and democratization of standard search technology}

The rise of OpenSource appears to have affected how much organizations will pay for traditional search tools, at the same time making them more affordable.

"Five years ago large companies spent a lot on Enterprise Search, it has been commoditized by very large IT vendors (shipping Enterprise Search virtually free with their content management systems) and OpenSource community, what companies are prepared to pay now is a lot less" [T4]

The possibilities that OpenSource ML and NLP algorithms present organizations was also raised.

"Organizations can apply state-of-the-art algorithms to their content using freely available opensource libraries, some things that were not possible 12 months ago, are now" [P3]

Informants were in general agreement that the landscape for enterprise search tooling had changed, with more choice and options driven by the OpenSource movement.

\section{Executive Understanding and Business Case}

The business case was highlighted by some informants as the key issue for Enterprise Search success. If this was not tied to the bottom line, business and executive management showed marginal/no interest, handing over governance to IT departments.

"Most organizations ignoring the problem and users accepting that fact, most information in the corporation is not being used as a corporate resource. There is a lack of executive understanding around what search is and the value it can bring" [P3]

The informants perceived there was a failure by executives to believe search is more than a technology or that search can impact the bottom line in a significant way. A lack of executive understanding was identified.

"Worked for one of world's largest Law companies recently, conducted an audit of Intranet and search. Every interview with a partner started with 'hope you are going to fix search because search is rubbish, we need a better search engine', but they had probably one of the best technically competent search engines around." [P1]

"Senior management see it as an IT problem, silver bullet that can fix everything" [02] , Need to think of bigger ecosystem, Enterprise Search highly dependent on other components" [05].

Differences between organizational sectors were raised.

"Nobody senior enough cares, low maturity still. Governments, Military and Intelligence sectors understand benefits more, maybe a little more academic less driven by profit, whereas many private sector companies see anything spent on KM as a cost" [T3]

"CIO for [redacted] at top table because he can drive revenue streams for the business. For retail, IT is the business. This does not exist in O\&G upstream because you don't have 
customers per se. IT is seen as a support function. So you don't have as much power as in other sectors" [010].

The failure by some organizations to align search business cases to work tasks was identified.

"Manufacturing think of 1 or 2 things. Either I have an Intranet of content (with HR stuff) or they consider search as front end of content management repository and want to stick a search engine in front of it. Problem with those two approaches, business case is non-obvious, does not fly. The Chief Financial Officer (CFO) does not want to pay for Intranet (so people can find pension benefit stuff) and content management is completely divorced from the business case. Point search at transactional systems, systems they use to create drawings, designs or testing plans, product introduction or product work process. If we can get clients thinking in that direction we may be able to sell something." [T2]

There was some disagreement whether enterprise search was mission critical.

"Need to find things faster, more efficiently, driver for Enterprise Search" [05]. "Not finding something in search does not stop them doing their job, they just do it slower, so it's [Enterprise Search] not absolutely crucial" [03].

This may relate to the use cases for enterprise search, which will be discussed later in this section.

\section{Business Influencers}

The criticality of business influencers inside the organization was highlighted.

"Taken a group of us in IT to raise the profile of search, met recently with $\mathrm{CIO}$, he had got message that search is important... everything we do depends on getting access to information, vital to our future. Been a struggle to move search from a nice to have, to intrinsic to everything we do" [08]

Several informants highlighted the benefits of having people in an organization that understood what was possible, business processes and executive management drivers (regardless of their reporting line).

\section{Ownership and Governance}

The different drivers of Information Technology (IT) groups, Knowledge Management (KM) and Business Users were identified.

"We generally find KM groups understand value of good search, with IT it's just an infrastructure component. Success we had was to target a core set of use cases, then solve them using search, rather than provide a generic platform" [T4]

"We had a leading search engine which was considered useless, though root causes were governance, training of the system, management of synonyms and user activity. We started to put right though our IT folk seems to have lost sight of the goal" [06].

"As far as IT are concerned, as long as the crawl is being done at the right time, latency of delivery is ok and it does not fall over in a disaster scenario things are fine...Not seen as a knowledge system" [P1] 
"There is a big gap between IT and business. Business does not understand what IT can offer, IT does not understand what the business wants. Search is the same, people don't understand what search can offer they base it on Google. Search is driven by IT" [01]

These in turn appear to influence the technology vendors.

"Vendors focused in selling to IT departments because that is where the budget is, something which is fast, handles big data all these capabilities, selling it to people who don't know what they bought. Yes, budgeting structure a factor". [P2]

The gap between the business and IT was repeatedly made by informants.

\section{Information Management and Knowledge Organization}

The criticality of information completeness and quality derived from underlying information management practices was emphasized by all three groups (technology vendors, practitioners and organizations).

"Useful to have governance at IM level, where search is part of IM roadmap" [01]

Information content volumes in the index was raised.

"As I'm out in the field doing studies for optimization, the most prevalent reason search is not working (probably won't believe me because I am a sales guy) in any organization is because individual content they want is not in the index. Invariably what happens, you raise bar of expectation, 'oh my god this is great' but users start to search for things not part of the project, start to complain." [T2]

The risks where underlying information management practices were poor was identified.

"After we went live with our search engine initially, legal closed it down as it was exposing sensitive information" [010]

"Problem we see is not from our experience on search engine side, but on side of content not being available or available in a way there is not sufficient metadata to bring up result" [07]

Along with the importance of domain vocabularies and taxonomies.

"Many search engines lack sophisticated semantic functionality to enable users to build thesauri, taxonomies, ontologies to tag content and leverage relationships. organizations frustrated when their brand new search does not work very well" [05]

Informants emphasized the nature of domain knowledge (teaching the search system) and quality content over algorithms to give search precise results. Particularly when looking for a single item.

\section{Information Literacy and behaviour}

The role of the actor (the user), their information literacy and human behaviour was raised by several informants as a factor/mechanism for poor Enterprise Search outcomes. Many informants expressed a view that tagging (classifying) information was key to search success, however getting people to do it was not so easy.

"Tagging...I think you are right on. Trash in trash out. Worked as a search consultant on a lot of projects large and small in US. I came to the realization it all boils down to one thing and one thing only and that is humans are lazy. If your experience and relevancy depends on a 
human action, it sounds good on paper, but in reality never pans out. Behaviour I have seen over years. I don't think anyone is really able to take it to the level that it could be on paper. Machine learning/entity extraction can help, but always fall short, behaviours are key, don't really know what the answer is for this one." [T1]

The challenges of trying to answer a query when only one to two words are added as a search query was a common point raised by informants.

"Zero in on question. 1.2 to 1.6 average keywords used in enterprise search; that is what makes facets critical, not getting enough critical information from users". [T2]

"People in enterprises do primitive searches, mostly single keyword searches, hard to find something meaningful with that, only $10 \%$ queries use facets" [07].

"Huge lack of awareness on how to search, the act of searching in everyone's mind is very simple" [02].

"There are skilled people, people keen to learn about search, but that is not majority of our 120,000 staff" [03].

Expectations of staff (users of the system) and search literacy in terms of understanding how the search systems works was mentioned by most informants.

\section{Enterprise Search Use Cases}

Four different use cases for enterprise search were raised by informants.

The traditional use case for enterprise search as a 'utility' was emphasized, where faceted search is key, but also the need to integrate with actions on that information once found.

"In the enterprise if you are searching for something, you want to act upon it. Want to make sure search is more than 10 blue links and that search, results in an action." [T1]

As well as tailoring the experience to personal networks (people centric).

"What's happening is this whole social evolution. Do we understand background and intent of searcher, perhaps we can build predictive search experience, notify you. Predictive versus triggered by user. This is next frontier, intelligent maps, scenarios, coping with bombardment of information overload which will cause dissatisfaction." [T4]

A use case to deliver specific task/domain (task centric) based contextual interfaces was raised along with image search.

"Get a patchwork in O\&G companies, tend to focus in on solutions that are engineer/scientist driven, we are going to let each unit/department/function figure out how they do stuff. You are not going to have a one size fits all, search is highly granular." [P2]

"Search is a Combination of structured and unstructured. Its Google like on Internet with one key difference, people don't want one search box, search based applications are prevalent. Common platform, silo's of value. Want to search through structured data like unstructured. Manufacturing use case, 'I' $m$ building this new design and I want to understand what parts we used before like this screw' that information is kept in structured database." [T2]

"Stuff you call Enterprise Search is nothing more than a utility. Output has to focus from text to contextual needs of the person that needs information in a mission critical environment. 
You need a different modality, capability - maps, data interactions, link analyses. Definition is not finding information, definition is to allow you to make an informed decision." [P2]

A use case to deliver answers was identified (answer centric).

"Once we have unlocked the code for what the true value is for Enterprise Search, believe that we will. We are building out to an answer machine. If you have a machine that can give you answers, that value is immediately obvious." [T3]

"Question and Answer has its place, not the same problem as search as you can only solve or calibrate a small amount of common questions, highly tailored" [T4]

A use case to deliver a discovery engine was postulated (topic/concept centric).

"Search is a recall engine, designed to help people find out about a topic, designed to find a needle in a haystack. If there are examples of putting two haystacks together and crafting a new needle, then it's a game changer." [T2]

Enterprise Search has only touched the surface, all sorts of possibilities for business intelligence at a task/domain driven level. [01]

This nature of enterprise search being more than a single 'Google interface' was emphasized.

"There is Enterprise Search where everyone uses the same interface, like wide and shallow, with a grey line to technical search narrow and deep that may have spatial/map based and other functionality, looking inside documents and applying automated intelligence" [08]

"There are many different types of users, mistake to try to be all things to everyone we need many different search task driven domain interfaces" [07].

Some informants felt new techniques such as 'answers' would replace existing methods (lists of results), whilst others saw them as complimentary.

\section{Search Tuning}

The importance of feedback, human relevance testing for constant search tuning was mentioned by all groups of informants.

"Those companies that do have a focus on search have a dedicated search team and do have a higher score from our studies." [T1]

"Lots of organizations take log data, but is that log data ever analysed and used to improve search? No" [P1]

The challenges in terms of awareness, difficulty and cost were raised.

"We were looking at adjusting ranking of search results based on metadata, scared we would knacker the ranking model, experimentation not easy" [06].

"We don't tend to look at causes, why people could not find information" [06]

"We don't have people looking at the logs, doing value add stuff. Was proposed to management, but unfortunately ClO turned it down, benefit did not justify the cost, did not yield short term benefits he wanted to prioritize other things". [03]

The themes described and their relationships are shown in Figure 1. 


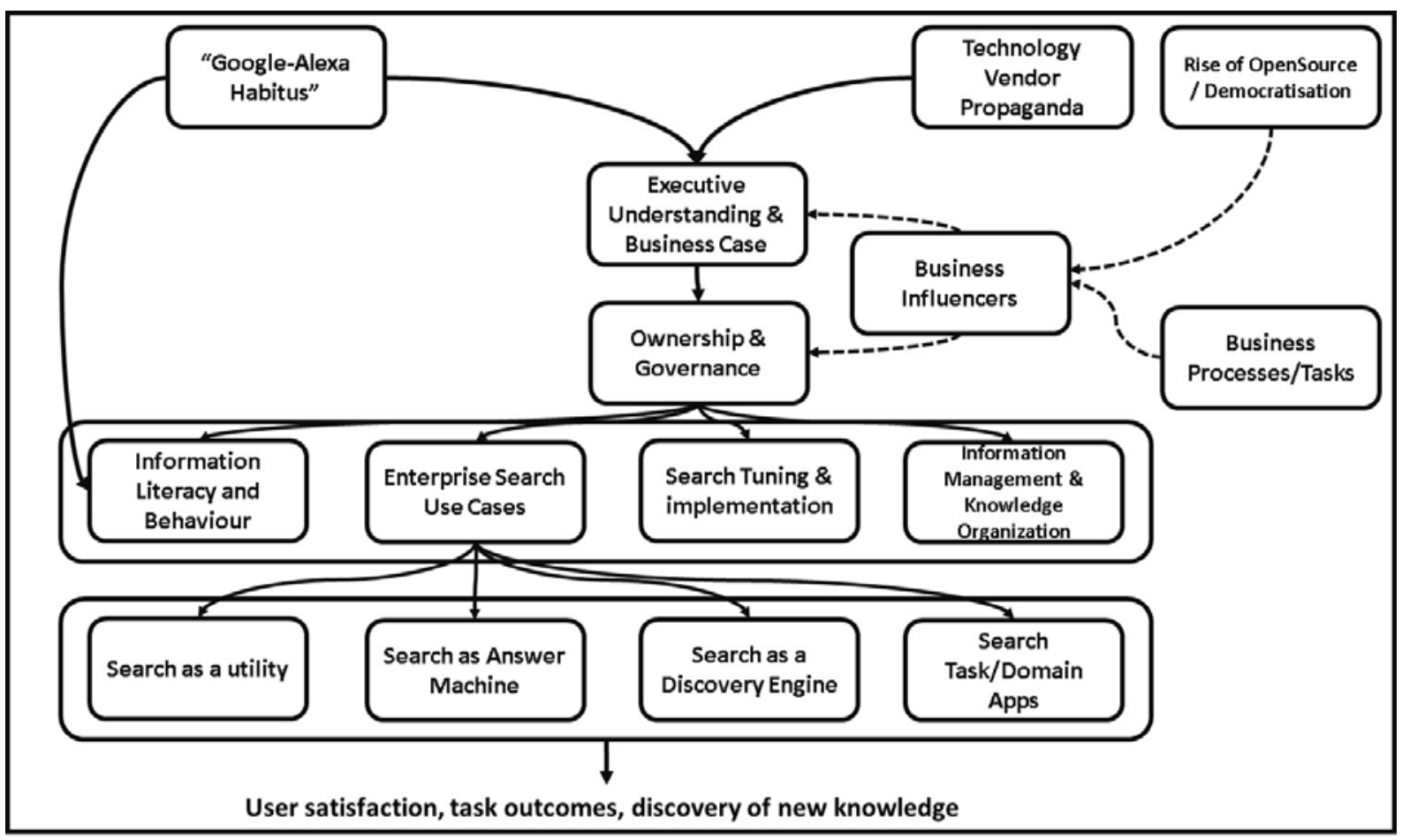

Figure 1 - Enterprise Search Themes and lines of influence from interviews showing the importance of internal business influencers in organizations (dotted lines)

The next section discusses the findings in context to the existing literature.

\section{DISCUSSION}

The study has provided confirmation of existing findings (White 2015, Stocker et al 2015, Cleverley and Burnett 2019) that in order to deliver a successful enterprise search deployment, it is likely that a 'systems thinking' approach considering information quality, user literacy, governance and technology is needed. Despite this, for many executives and end users in organizations, enterprise search still appears synonymous with technology.

The results show evidence for a four level 'use case' for enterprise search. This consists firstly, of the standard utility applicable to all, a 'Google-like' interface producing ranked lists of multimedia results. This is the original case often discussed through case studies in the literature (Dale 2016, White 2015).

The second use case is another utility, 'Alexa-like' Question and Answering (Q\&A), enabled through recent technological breakthroughs of NLP, tailored chatbots (conversational assistants) and more widely applicable neural answering (Seo et al 2017). There are few to no published enterprise case studies, reflecting its maturity and emerging status (Landqvist 2019, Gualtieri 2017).

The third use case is context-rich specific search task/domain-based applications, as discussed by Grefenstette and Wilber (2011). These enterprise search tools are more likely to search and exploit structured data in databases as well as unstructured information (as that is more likely to be domain specific) tailoring it to common repeatable questions relevant to that task. Search results are likely to be returned in deep context such as in time, space and even Augmented Reality (AR). In some cases, these search task applications may be a new take on some legacy dashboards and portals that were created using different means. In other cases, they may enable us to put a lens and 'digital experience' over our information that was not hitherto possible. This is not simply the vertical 'industry specific' search discussed by Betts (2018) but task/domain focused search driven apps. 
The fourth use case is one of business intelligence and discovery. This use case for enterprise search does not seek to find a document or answer that already exists explicitly in the repositories, rather it seeks through advanced analytics to surface new knowledge such as an analogue. This is knowledge that was not necessarily known to the organization a priori; connections that compare, contrast, highlight contradictions and infer automatically. Not just user driven discovery, but also automated discovery - intelligence (of a sort). This is the use case alluded to by Mukherjee et al (2013) to identify similar cases, questions that the traditional IR based search paradigm struggles to answer. The combined model is shown in Figure 2.

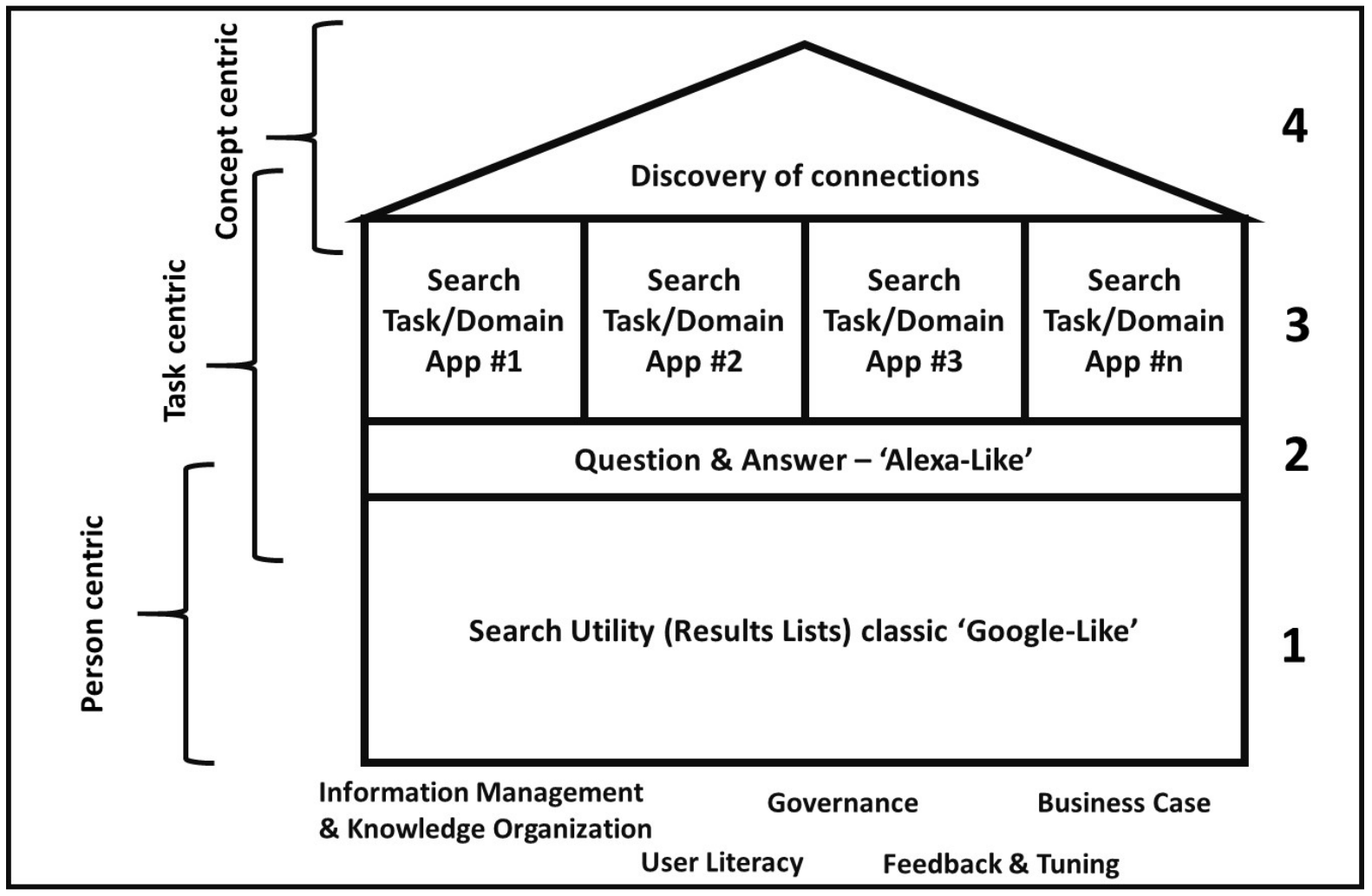

Figure 2 - Multimedia 4-Layer Model for Enterprise Search Use Cases in an organization, underpinned with a Systems Thinking approach towards the search environment.

Any search deployment could be made up of a single layer in this model or utilize parts (or all) of the 4 use cases. Rather than one or the other (considering theses competing approaches) it is likely to be one and the other, addressing a spectrum of use cases. Use cases 3 and 4 are likely to involve rich visualizations. These may potentially include targeted Augmented Reality (AR) deployments in some industries (Betts 2018), enabling the Digital Twin concept, although informants were largely silent on this as being in the forefront of their minds. Use cases 1 and 2 are likely to gain increasing use from wearable technology.

What some practitioners and vendors are now terming 'insight engines' or 'cognitive search' (Tetu 2016, Gualtieri 2017) are simply slices through these enterprise search use cases. Whether the new terminology is a fad or will stick, remains to be seen.

The limitations of the study include a focus on large organizations. The challenges faced by much smaller organizations may have some different themes. Another limitation is that senior executives (Vice Presidents/CEO's) were not interviewed, presenting an area for further research. 
The next section assesses the contribution of the study and implications for both academia and practice.

\section{CONCLUSIONS}

The contribution of the study is twofold. Firstly, the study has brought together views from three key informant groups related to enterprise search for the first time to understand current challenges and future directions. Secondly, a novel model is presented for enterprise search use cases supported by the evidence, which provides a new take on 'enterprise search' to add to the discourse. This model could be used to reframe how enterprise search is perceived, influencing strategies, deployments and conceptual models.

Enterprise search concepts have come a long way from definitions that restricted it to an Information Retrieval problem relating to web pages and documents on an Intranet. The explosion of information within organizations (both unstructured, structured and images) and freely available machine learning capabilities offer up many more possibilities.

The original enterprise search use case remains; find information in the enterprise 'like Google' quickly and efficiently. This remains elusive in many cases and may be more dependent on information management practices in an organization than technology per se. Search in the enterprise is complex, multidisciplinary and resistant to change, requiring holistic approaches. When we walk into a library, we do not tend to approach the librarian and shout one word at them! This is what we are currently doing with most enterprise search systems.

In some cases, conversational Q\&A use cases may stand a better chance at understanding user intent supporting mobile and voice search, but within the enterprise it is likely to be one approach among many. Feedback mechanisms and constant learning loops at all levels in the system (including search literacy) are likely to be necessary to deliver the most effective search outcomes.

The consumer Internet based world is always likely to be one step ahead of the enterprise due to adoption lag and commercial models; it may be inevitable that organizations will have to cultivate search behaviours that suit their tools and practices. Organizations that have a more search literate user base may do better than those that do not.

Business cases which have been hard to develop in places, may gain fertile ground in search task/domain applications supporting digital transformation of work practices. The role of business influencers who are aware of the possibilities and business needs (not just technological) are likely to be a critical success factor in evolving enterprise search within the organization.

The discovery of new knowledge in these vast corpuses of information has already led to the creation of new business models for some organizations - a gamechanger. This could tip the balance in moving enterprise search from nice to have, to mission critical.

\section{ACKNOWLEDGEMENTS}

The authors would like to thank all participants, without which this research would not have been possible, that remain anonymous for confidentiality reasons.

\section{REFERENCES}

BETTS, A., 2018. The future of enterprise search: Visual, voice and vertical. [online]. Available from: https://www.searchenginejournal.com/future-of-enterprise-search/260871/ [accessed April 2019] 
CLEVERLEY, P.H., BURNETT, S. and MUIR, L., 2017. Exploratory searching in the enterprise: A study of User Satisfaction and Task Performance. Journal of the Association for Information Science and Technology (JASIST), 68(1): pp. 77-96.

CLEVERLEY, P.H. and BURNETT, S., 2019. Enterprise Search and Discovery Capability: The factors and generative mechanisms for user satisfaction. Journal of Information Science, 45(1): pp. 29-52.

DALE, E., 2013. The importance of constant measurement in search relevance. A longitudinal case study. Enterprise Search Summit (ESS) May 21-22 2013. New York, USA. [online]. Ernst \& Young. Available from: http://www.enterprisesearchsummit.com/Spring2013/Presentations.aspx [accessed June 2018].

DALE, E., 2016. The voice of the customer: EY Case Study. Enterprise Search Summit 14-17 November 2016: Washington DC, USA. [online]. Available from: http://www.enterprisesearchanddiscovery.com/2016/presentations.aspx [accessed December 2018].

DIMAIO, P., 2009. Exobrain definition. [online]. Urban Dictionary. Available from: http://www.urbandictionary.com/define.php?term=Exobrain [accessed January 2019].

DÖRK, M., CARPENDALE, S. and WILLIAMSON, C., 2011. The Information Flaneur: A Fresh Look at Information Seeking. Computer Human Interaction (CHI). May 7-12 2011: Vancouver, BC, Canada, pp. $1-10$.

FINDWISE, 2016. Enterprise Search and findability survey. [online]. Available from: https://findwise.com/Enterprise-Search-Findability-Report-2016 [accessed April 2019].

GANTZ, J. and REINSELL D., 2011. Extracting Value from Chaos: Report ID 1142. [online]. International Data Corporation (IDC). Available from: https://www.emc.com/collateral/analystreports/idcextracting-value-from-chaos-ar.pdf [accessed January 2019].

GÅRDELÖV, F., LARSSON, V. and STENMARK, D., 2015. "Why should Organisations Govern Enterprise Search?". [online]. Gothenburg University Publications. Available from: http://gup.ub.gu.se/records/fulltext/217057/217057.pdf [accessed January 2019].

GARTNER, 2011. Information Management Goes 'Extreme': The Biggest Challenges for 21st Century CIOs. [online]. Available from: http://togetherwepass.co.za/http://togetherwepass.co.za/wpcontent/uploads/filebase/certified_off ice_manager/management/study_notes_/Extremelnformation-Management\%20Extreme.pdf [accessed August 2018].

GARTNER, 2015. 'Insight Engines' Will Power Enterprise Search That is Natural, Total and Proactive. Report G00275488. Restricted Report

GOOGLE, 2015. Google Search Statistics. [online]. Real Time Statistics Project. Available from: http://www.internetlivestats.com/google-search-statistics/ [accessed August 2017].

GRANT, S. and SCHYMIK, G., 2014. Using Work System Theory to Explain Enterprise Search Dissatisfaction. Proceedings of the Information Systems Educators Conference (ISECON). 6-9 November 2014: Baltimore, Maryland, USA, pp. 1-11.

GREFENSTETTE, G. and WILBER, L., 2011. Search-Based Applications: At the Confluence of Search and Database Technologies. In: MARCHIONINI, G., Ed. Synthesis Lectures on Information Concepts, Retrieval, and Services. USA: Morgan \& Claypool Publishers. 
GUALTIERI, M., 2017. Cognitive Search is the Al Version of Enterprise Search. Forrester Insights. [online]. Available from: https://go.forrester.com/blogs/17-06-12cognitive_search_is_the_ai_version_of_enterprise_search/

HAWKING, D., 2004. Challenges in Enterprise Search. Proceedings of Fifteenth Australasian Database Conference (ADC2004). January 18-22 2004. Dunedin, New Zealand. Conferences in Research and Practice in Information Technology 27, pp. 15-24.

HILLIS, K., PETIT, M. and JARRETT, K., 2013. Google and the Culture of Search. UK: Routledge.

KEHOE., 2018. Enterprise search in 2018 what a strange trip it's been. CMS Wire. [online] Available from: https://www.cmswire.com/information-management/enterprise-search-in-2018-what-a-longstrange-trip-its-been/

KRUSCHWITZ, U. and HULL,. 2017. Searching the Enterprise. Foundations and Trends in Information Retrieval 2017; 11(1): pp. 1-142.

LANDQVIST, F., 2019. Open or opaque Artificial Intelligence. Findwise Blog. [online]. Available here: https://findwise.com/blog/

MARR, B., 2018. The amazing digital transformation of Elsevier, from publisher to tech company. [online]. Available from: https://www.elsevier.com/connect/bernard-marr-on-the-amazing-digitaltransformation-of-elsevier-from-publisher-to-tech-company

MEZA, D. and BERNDT, S., 2014. National Aeronautics and Space Administration (NASA) Johnson Space Centre (JSC) Search System Usability Case Study. [online]. Available from: http://ntrs.nasa.gov/archive/nasa/casi.ntrs.nasa.gov/20140007413.pdf [accessed May 2018].

MILES, M. and HUBERMAN, M., 1994. Qualitative data analysis: An expanded sourcebook. 2nd ed. Thousand Oaks: SAGE.

MINDMETER, 2011. Mind the Enterprise Search Gap. [online]. Available from: http://www.smartlogic.com/resource-center [accessed June 2018].

NORLING, K. and BOYE, J., 2013. Findability Survey. Findability Day. Stokholm: Findwise. Available from:http://sharepointtaxonomy.com/Data/Sites/2/downloads/enterprise_search_and_findability_s urvey _2013.pdf [accessed August 2018].

PATTON, M.Q., 2015. Qualitative Research \& Evaluation Methods. 4th ed. USA: Sage.

PHILLIPSON, C., 2014. Enterprise Search: 14 Industry Experts Predict the Future of Search. [online]. Available from: http://www.docurated.com/enterprise-search/enterprise-search-14industryexperts-predict-future-search [accessed August 2018].

POTTER, G. and LOPEZ, J., 2001. After postmodernism: the millennium. In: LOPEZ, G., Ed. After Postmodernism: an introduction to Critical Realism. London, UK: The Athlone Press.

ROMERO, L., 2013. Improving Enterprise Findability. [online]. AQPC. Available from: https://www.apqc.org/sites/default/files/files/Improving\%20Enterprise\%20Findability\%20\%20APQC .pdf [accessed March 2017].

SAYER, A., 2000. Realism and Social Science. London, UK: Sage. 
SELTZER, M. and MURPHY, N., 2009. Hierarchical file systems are dead. Proceedings of the 12th conference on Hot topics in operating systems HotOS '09. May 18-20 2009. Monte Verità, Switzerland, pp. 1-5.

SEO, M.J., et al 2017. Attention Flow for Machine Comprehension. Conference Paper ICLR. [online]. Available from: https://arxiv.org/abs/1611.01603

SMITH, C. and ELGER, T., 2012. Critical Realism and Interviewing Subjects. [online]. School of Management, Royal Holloway University of London. Available from: http://pure.rhul.ac.uk/portal/files/12460828/Smith_Chris_Critical_Realism_and_Interviewing_SOM _ Working_Paper.pdf [accessed March 2018].

STOCKER, A. et al., 2015. Exploring barriers of Enterprise Search implementation: a qualitative user study. Aslib Journal of Information Management, 67(5), pp. 470-491.

TAO, F. et al., 2019. Digital Twin in Industry: State-of-the-art. IEEE Transactions on Industrial Informatics. 15(4), pp. 2405-2415

TETT, G., 2016. The Silo Effect. UK: Abacus.

TETU, L., 2016. Creating the Intelligent Workplace: Think Proficiency not Efficiency. Enterprise Search Summit 14-17 November 2016: Washington DC, USA. [online]. Available from: http://www.enterprisesearchanddiscovery.com/2016/presentations.aspx [accessed December 2018].

WHITE, M., 2012. Enterprise Search. California, USA: O’Reilly.

WHITE, M., 2015. Critical success factors for Enterprise Search. Business Information Review, 32(2), pp. $100-118$

ZARRABIAN, M., 2019. Enterprise search trends to look for in 2019. [online]. Available from: https://www.information-age.com/enterprise-search-trends-123477875/ 